\title{
TNF- $\alpha$ induces CXCL1 chemokine expression and release in human vascular endothelial cells in vitro via two distinct signaling pathways
}

Huey-ming LO ${ }^{1,2}$, Tsung-hsuan LAI ${ }^{1,3,4}$, Chih-hung $\mathrm{LI}^{1}$, Wen-bin WU ${ }^{1, *}$

\begin{abstract}
${ }^{1}$ School of Medicine, Fu-Jen Catholic University, New Taipei City, Taiwan, China; ${ }^{2}$ Section of Cardiology, Department of Internal Medicine, Shin Kong Wu Ho-Su Memorial Hospital, Taipei, Taiwan, China; ${ }^{3}$ Department of Obstetrics and Gynecology, Cathay General Hospital, Taipei, Taiwan, China; ${ }^{4}$ Institute of Systems Biology and Bioinformatics, National Central University, Jhongli City, Taoyuan, Taiwan, China
\end{abstract}

Aim: Chemokines usually direct the movement of circulating leukocytes to sites of inflammation or injury. CXCL1/GRO- $\alpha$ has been shown to be upregulated in atherosclerotic lesions and various cancers. The aim of this study was to investigate the mechanisms underlying the TNF- $\alpha$-induced release of CXCL1 from human vascular endothelial cells in vitro.

Methods: Human umbilical vein endothelial cells (HUVECs) were treated with different proinflam-matory mediators and growth factors. CXCL1 expression and secretion were determined using RT-PCR and ELISA, respectively. TNF- $\alpha$-induced cell signaling was assayed with Western blotting. Cell viability/growth was determined using MTT assay. Monocyte migration was measured with transwell migration assay.

Results: Among the 17 mediators and growth factors tested, TNF- $\alpha$, LPS and thrombin induced marked increase in CXCL1 release from HUVEC cells. TNF- $\alpha(2,5 \mathrm{ng} / \mathrm{mL})$ induced CXCL1 release and mRNA expression in the cells in concentration- and time-dependent manners. TNF- $\alpha(5 \mathrm{ng} / \mathrm{mL})$ caused activation of JNK, p38 MAPK, PI3K and Akt, whereas pretreatment with JNK inhibitor (SP600125), p38 MAPK inhibitor (SB202190) or PI-3K inhibitor (LY294002) significantly suppressed TNF- $\alpha$-induced CXCL1 release from the cells. But only SP600125 significantly reduced TNF- $\alpha$-induced CXCL1 mRNA expression in the cells. Moreover, dexamethasone (up to 500 $\mathrm{nmol} / \mathrm{L}$ ) failed to affect TNF- $\alpha$-induced CXCL1 release from the cells. In functional studies, recombinant CXCL1 enhanced HUVEC proliferation, and both recombinant CXCL1 and TNF- $\alpha$-induced CXCL1 from HUVECs attracted human monocyte migration. Conclusion: TNF- $\alpha$ stimulates CXCL1 release from human ECs through JNK-mediated CXCL1 mRNA expression and p38 MAPK- and PI-3K-mediated CXCL1 secretory processes.

Keywords: chemokine; CXCL1; GRO- $\alpha$; TNF; vascular endothelial cell; JNK; p38 MAPK; PI3K; monocyte; dexamethasone

Acta Pharmacologica Sinica (2014) 35: 339-350; doi: 10.1038/aps.2013.182; published online 3 Feb 2014

\section{Introduction}

Tumor necrosis factor (TNF) is a protein consisting of 157 amino acids and is synthesized as a membrane-bound protein (pro-TNF) that is released by TNF-converting enzyme (TACE)-mediated cleavage. It is a multifunctional cytokine that plays important roles in diverse cellular events such as cell survival, proliferation, differentiation, and death ${ }^{[1]}$. TNF is a proinflammatory cytokine that may play roles in the pathogenesis of atherosclerosis ${ }^{[2]}$ and cancer ${ }^{[1]}$. Its atherosclerosispromoting properties might result from its actions on leuko-

\footnotetext{
* To whom correspondence should be addressed.

E-mail wenbin@mail.fju.edu.tw

Received 2013-06-20 Accepted 2013-10-10
}

cytes, endothelial cells, and adipocytes ${ }^{[3]}$. TNF can also be detected in malignant and/or stromal cells in human ovarian, breast, prostate, bladder, and colorectal cancers as well as in lymphoma and leukemia, often in association with interleukin (IL)-1 and IL-6 and macrophage colony-stimulating factor ${ }^{[4]}$.

CXCL1, also known as growth-related oncogene protein- $\alpha$ (GRO-a), is a polypeptide that was initially isolated from human melanoma cells. CXCL1 is one of the members of chemokines (chemotactic cytokines), which are small heparinbinding proteins that generally direct the movement of circulating leukocytes to sites of inflammation or injury ${ }^{[5]}$ CXC chemokines (designated ELR+), such as CXCL1 and CXCL8, can bind to CXCR1 and CXCR2 on neutrophil surface ${ }^{[6]}$. ELR+ chemokines are primarily chemotactic for endothelial cells and 
neutrophils. These chemokines are potent promoters of angiogenesis, as the recruited neutrophils are known to synthesize and store angiogenic molecules such as vascular endothelial growth factor (VEGF)-A ${ }^{[7,8]}$.

In an early study, human endothelial cells were reported to be capable of synthesizing and secreting CXCL1 following stimulation by TNF and other cytokines ${ }^{[9]}$. However, its regulatory mechanism remains unclear. Recently, it has been reported that CXCL1/GRO- $\alpha$ is upregulated in atherosclerotic lesions and plays a central role in macrophage accumulation and lesion progression ${ }^{[10]}$. Moreover, under pathological conditions, various cancers and/or cancer cells express different chemokines and chemokine receptors, which modulate leukocyte infiltration of the tumor microenvironment as well as tumor growth and metastasis. For example, CXCL1 has been reported to be expressed in melanoma as well as breast, colon, and ovarian cancers ${ }^{[7]}$. CXCL1 has also been shown to play a pivotal role in thrombin-induced angiogenesis ${ }^{[11]}$.

In this study, we screened the abilities of several proinflammatory mediators and growth factors to induce CXCL1 release by human umbilical vein endothelial cells (HUVECs). Among these mediators, we found a marked enhancing effect by TNF-a. Therefore, the effect of TNF-a on CXCL1 release by HUVECs was further investigated in this study. We showed that TNF-a induced CXCL1 release through transcriptional and secretory regulation in HUVECs. The possible underlying mechanisms were determined, including the involvement of the JNK-, p38 MAPK-, and PI-3K-related signaling pathways.

\section{Materials and methods Materials}

Angiotensin II, thrombin, bradykinin, PD98059, SB202190, SP600125, cycloheximide, 3-[4,5-dimethylthiazol-2-yl]-2,5-diphenyltetrazolium bromide (MTT), actinomycin D, and wortmannin were purchased from Sigma Chemical Co (St Louis, MO, USA). SU3327 was purchased from Tocris Bioscience (Bristol, UK). LY2228820 was purchased from Selleck Chemicals (Houston, TX, USA). Human epidermal growth factor (EGF), insulin-like growth factor (IGF), basic fibroblast growth factor (bFGF), and transforming growth factor (TGF)- $\beta$ were purchased from Invitrogen Life Technologies (Carlsbad, CA, USA). ATP and ADP were purchased from Affymetrix USB Products (Santa Clara, CA, USA). U46619 (TXA 2 analog) was purchased from Enzo Life Sciences, Inc (Farmingdale, NY, USA). Antibodies (Abs) raised against phosphoinositide-3 kinase (PI3K) (sc-423), mitogen-activated kinase phosphatase-1 (MKP-1) (sc-1102), and phospho-ERK1/2 (sc-7383) were purchased from Santa Cruz Biotechnology (Santa Cruz, CA, USA). Abs raised against total p38 MAPK (\#9212), phospho-p38 MAPK (\#9216), phospho-JNK (\#9255), phospho-PI3K (\#4228), and phospho-Akt (\#4058) were purchased from Cell Signaling Technology, Inc (Danvers, MA, USA). Human recombinant IP-10, SDF-1, Platelet Derived Growth Factor (PDGF), leptin, and TNF- $\alpha$ and an Ab against ERK1/2 (AF1576) were purchased from R\&D systems, Inc (MN, USA). An Ab against a-tubulin (CP06) was purchased from Calbiochem EMD Bio- sciences Inc (San Diego, CA, USA).

\section{Cell culture}

HUVECs were prepared and characterized by a method described previously ${ }^{[12]}$. Briefly, umbilical cord veins were cannulated and flushed with cord buffer to remove blood and then filled with $0.1 \%$ collagenase (type I) for $10 \mathrm{~min}$ at $37^{\circ} \mathrm{C}$. Isolated endothelial cells, which were positive for von Willebrand factor antigen by immunofluorescent staining, were maintained in M199 containing $20 \%$ FBS (fetal bovine serum), $30 \mu \mathrm{g} / \mathrm{mL}$ endothelial cell growth supplement (ECGS), $4 \mathrm{mmol} / \mathrm{L}$ L-glutamine, 100 $\mathrm{U} / \mathrm{mL}$ penicillin, $100 \mu \mathrm{g} / \mathrm{mL}$ streptomycin, and fungizone (250 $\mathrm{ng} / \mathrm{mL}$ ) (Invitrogen Life Technologies, Carlsbad, CA, USA). Cells between the second and fourth passages were used in this study. Human THP-1 monocytes and the A549 human epithelial cell line were obtained from the Food Industry Research and Development Institute. THP-1 monocytes were cultured in RPMI-1640 medium with $2 \mathrm{mmol} / \mathrm{L}$ L-glutamine, $1.5 \mathrm{~g} / \mathrm{L}$ sodium bicarbonate, $4.5 \mathrm{~g} / \mathrm{L}$ glucose, $10 \mathrm{mmol} / \mathrm{L}$ HEPES, and $1.0 \mathrm{mmol} / \mathrm{L}$ sodium pyruvate, and 10\% FBS. A549 epithelial cells were cultured in DMEM/Ham's F-12 nutrient mixture containing $10 \%$ FBS, antibiotics, and fungizone.

\section{Measurement of secreted CXCL1 in culture medium by ELISA}

CXCL1 release in culture medium was determined using a human CXCL1 ELISA Development Kit (R\&D Systems, Inc, MN, USA) according to the manufacturer's protocol. Briefly, HUVECs were treated with vehicle or TNF-a. The culture medium was collected and centrifuged, and CXCL1 release in culture medium was measured. The product of this enzymatic reaction is yellowish in color and absorbs strongly at 412 $\mathrm{nm}$. The intensity of the color is proportional to the amount of CXCL1 present in the well during the incubation. The absolute concentration of CXCL1 in the HUVEC culture medium was calculated from the standard curve.

\section{Cell viability and growth assay}

To determine HUVEC viability, HUVECs reaching 95\% confluency were treated with inhibitors for the indicated time intervals. To measure HUVEC proliferation, HUVECs reaching $50 \%$ confluency were incubated with the indicated concentrations of CXCL1. After removing the culture media, the number of viable cells was determined using an MTT assay. Briefly, cells were incubated with $0.5 \mathrm{mg} / \mathrm{mL}$ MTT for $2 \mathrm{~h}$ at $37^{\circ} \mathrm{C}$. Formazan crystals resulting from MTT reduction were dissolved by adding DMSO. The absorbance of the supernatant was then measured spectrophotometrically in an ELISA reader at $550 \mathrm{~nm}$.

\section{Cell lysate preparation and Western blot analysis}

Cell lysate was prepared as previously described ${ }^{[13]}$. Total proteins were separated by electrophoresis on SDS-polyacrylamide gels, electroblotted onto PVDF membranes, and then probed using a primary $\mathrm{mAb}$. Immunoblots were detected using an enhanced chemiluminescence reagent (Perkin-Elmer, 
Waltham, MA, USA). For some experiments, membranes were stripped with a striping buffer $(62.5 \mathrm{mmol} / \mathrm{L}$ Tris- $\mathrm{HCl}, \mathrm{pH}$ 6.7, 2\% SDS, and $100 \mathrm{mmol} / \mathrm{L} \beta$-mercaptoethanol), washed, and reprobed with Abs to examine the levels of a-tubulin or the corresponding total proteins and developed as described above.

Reverse transcription-polymerase chain reaction (RT-PCR) analysis of CXCL1 mRNA expression

Oligonucleotide PCR primers targeting human CXCL1 and $\beta$-actin were synthesized. The forward and reverse primers for CXCL1 were 5'-GCCCAAACCGAAGTCATAGCC-3' and 5'-ATCCGCCAGCCTCTATCACA-3', and the forward and reverse primers for $\beta$-actin were $5^{\prime}$-ATCATGTTTGAGACCTTCAA-3' and 5'-CATCTCTTGCTCGAAGTCCA-3', respectively. Total RNA from HUVECs was extracted using TRIzol reagent (Invitrogen Technologies, USA), and reverse transcription was performed using the Superscript III FirstStrand Synthesis System (Invitrogen Technologies, USA). Briefly, aliquots of 1-2 $\mu \mathrm{g}$ of total RNA were incubated with random hexaprimers for $10 \mathrm{~min}$ at $65^{\circ} \mathrm{C}$ and immediately chilled on ice. After primer annealing, RNA was reverse transcribed by the reverse transcriptase. Reactions were stopped, and RNase $\mathrm{H}$ was added to remove RNA. Aliquots of transcribed cDNA were subjected to PCR in a $25 \mu \mathrm{L}$ reaction mixture containing reaction buffer, dNTPs, primers, and Taq DNA polymerase (Genet Bio, Korea). PCR was performed with a hot start at $94^{\circ} \mathrm{C}$ for $5 \mathrm{~min}$ and then with 30 cycles of denaturation at $94^{\circ} \mathrm{C}$ for $1 \mathrm{~min}$, annealing at $56^{\circ} \mathrm{C}$ for $1 \mathrm{~min}$, and elongation at $72^{\circ} \mathrm{C}$ for $1.5 \mathrm{~min}$ in an ABI 7200 Thermal Cycler (Applied Biosystems, Foster city, CA, USA). The amplification products were then analyzed by gel electrophoresis in $2 \%$ agarose.

\section{SiRNA transfection}

ON-TARGET plus SMARTpool JNK (gene id: 5599) and negative control siRNA were purchased from Dharmacon RNAi Technologies (Thermo Fisher Scientific, USA), and SignalSilence ${ }^{\circledR}$ p38 MAPK siRNA and the control siRNA were purchased from Cell Signaling Technology, Inc (Danvers, MA, USA). Transfection was performed according to the manufacturer's protocol. HUVECs were seeded in 24-well plates for incubation overnight in complete medium. Cell cultures were transfected with control siRNA or the indicated siRNA (100 $\mathrm{nmol} / \mathrm{L}$ ) for $48 \mathrm{~h}$ using the DharmaFECT transfection reagent. After the cells were transfected, they were treated with vehicle or TNF-a, and the culture media were collected and analyzed by ELISA.

\section{Measurement of monocyte migration}

A monocyte migration assay was performed using a modified Boyden chamber apparatus (Transwell apparatus, $8.0-\mu \mathrm{m}$ pore size, Falcon). The lower face of the upper chamber (Transwell insert) was coated with fibronectin $(20 \mu \mathrm{g} / \mathrm{mL})$ for $30 \mathrm{~min}$ in a laminar flow hood and was loaded with monocytes $\left(2.5 \times 10^{5}\right.$ cells $/ \mathrm{mL}$ ). The upper chamber was attached to the lower chamber, which was seeded with/without HUVECs filled with serum-free or TNF-a-containing medium. Both chambers contained vehicle or the indicated inhibitor. The coculture system was allowed to incubate at $37^{\circ} \mathrm{C}$ for $16 \mathrm{~h}$. In some experiments, monocyte migration was examined in this system with the lower chamber only filled with medium and recombinant CXCL1. All nonmigrant monocytes were removed from the upper face of the Transwell membrane with a cotton swab, and migrated monocytes were fixed and stained with $0.5 \%$ toluidine blue in $4 \%$ paraformaldehyde. Migration was quantified by counting the number of stained cells in each of 100 high-power fields (HPFs) under a phase-contrast microscope (Nikon Eclipse Ti-S, Japan) and photographed.

\section{Statistical analysis}

Data are expressed as the mean \pm standard error (SEM). The means of two groups of data were compared using the unpaired, two-tailed Student's $t$-test.

\section{Results}

TNF- $\alpha$, LPS, and thrombin induce CXCL1 release by human vascular endothelial cells

To investigate the proinflammatory cytokines and growth factors that affect CXCL1 release by human vascular endothelial cells, an ELISA was used to measure CXCL1 in HUVEC culture medium. As shown in Figure 1, among these tested mediators, TNF-a, LPS, and thrombin induced a marked increase in CXCL1 release in HUVEC culture medium. Other mediators, including IP-10, SDF-1, leptin, growth factors (bFGF, VEGF, IGF, and EGF), angiotensin II (Ang II), U46619 (a thromboxane $\mathrm{A}_{2}$ analog), and purinoceptor agonists (ATP/ADP) did not induce any significant increases in CXCL1 release. Because of the significance and importance of TNF- $\alpha$ in endothelial

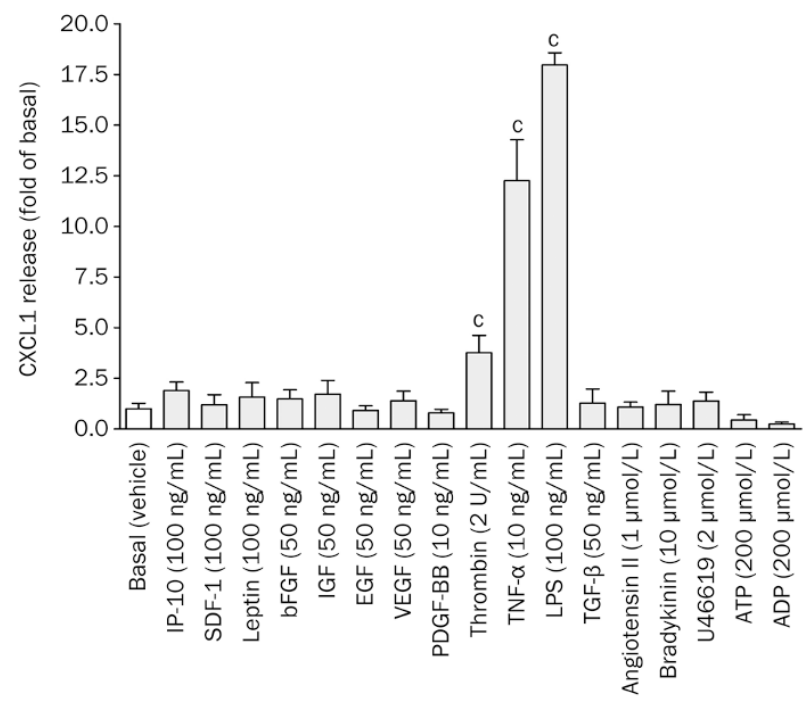

Figure 1. Effects of various mediators on CXCL1 release in HUVECs. Cells were treated with the indicated mediators for $16 \mathrm{~h}$. CXCL1 release in the culture medium was measured by ELISA $(n=3-4)$. ${ }^{c} P<0.01$ as compared with vehicle treatment only (basal). 
inflammation during atherosclerosis, its effect and mechanism of action were investigated.

Next, we examined the concentration- and time-dependent effects of TNF-a on HUVECs. As shown in Figure 2A, TNF-a increased CXCL1 release in a concentration-dependent manner; $1 \mathrm{ng} / \mathrm{mL}$ of TNF-a was sufficient to induce CXCL1
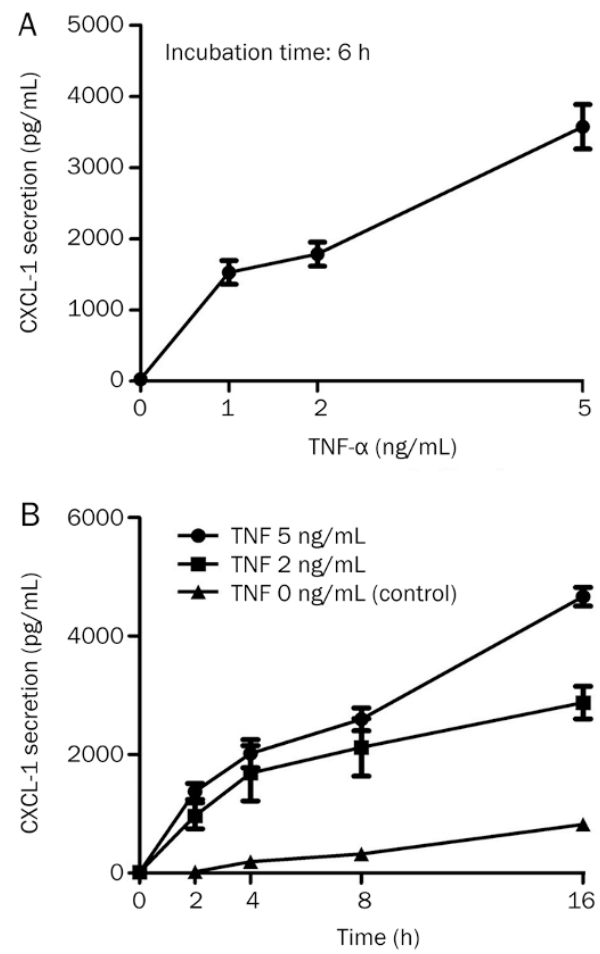

C
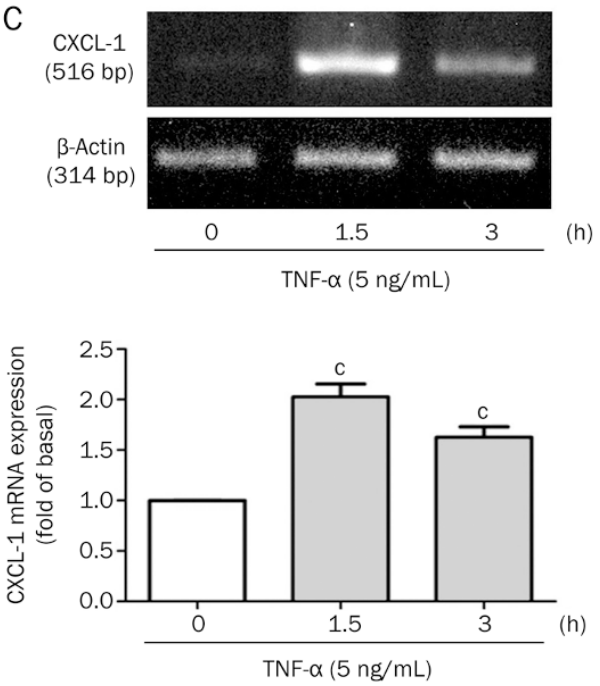

Figure 2. Concentration- and time-dependent effects of TNF- $\alpha$ on CXCL1 protein secretion and mRNA expression. HUVECs were treated with PBS or TNF- $\alpha$, and the culture media were analyzed by (A and B) ELISA. Total RNA was extracted and analyzed by (C) RT-PCR. CXCL1 mRNA levels were determined by densitometry. The data are the mean $\pm \operatorname{SEM}(n=3) .{ }^{c} P<0.01$ vs $\mathrm{Oh}$. release. Moreover, TNF- $\alpha$ increased CXCL1 release in a timedependent manner; a significant increase was observed during a short-term (2-h) incubation, reaching a plateau after $8 \mathrm{~h}$ of treatment and remaining stable through $16 \mathrm{~h}$. To further examine whether TNF- $\alpha$ induced CXCL1 mRNA expression, HUVECs were treated with TNF-a for 1.5 or $3 \mathrm{~h}$, and CXCL1 and $\beta$-actin mRNA expression was evaluated by RT-PCR. As shown in Figure 2B, CXCL1 mRNA was apparently upregulated by TNF- $\alpha$ at $1.5 \mathrm{~h}$ but slightly decreased at $3 \mathrm{~h}$, whereas $\beta$-actin mRNA expression was not affected. This suggests that TNF-a might affect CXCL1 expression through transcriptional regulation.

\section{Effect of signaling inhibitors on TNF- $\alpha$-induced CXCL1 release} and expression in HUVECs

To investigate the possible signaling pathways involved in the induction of CXCL1 by TNF-a, signaling inhibitors targeting MAPKs, PI3K, protein kinases, the NF-KB signaling pathway, DNA transcription, and protein translation were used. Among these inhibitors, the JNK inhibitor (SP600125), p38 MAPK inhibitor (SB202190), PI3K inhibitor (LY294002), tyrosine kinase inhibitor (genistein), activator protein-1 (AP1) transcription factor inhibitor (tanshinone IIA), protein translation inhibitor (cycloheximide), and DNA transcription inhibitor (Act D) significantly inhibited the CXCL1 release induced by TNF-a. The inhibition was not due to a decrease of cell viability because the inhibitors did not affect cell viability (Figure 3A). However, some of these inhibitors showed a different inhibitory profile for LPS-induced CXCL1 secretion (Figure 3B). For example, PD98059 and BAY11-7085 inhibited LPS-induced CXCL1 release but did not affect TNF-ainduced CXCL1 release, indicating that these inhibitors were specific and were effective at the tested concentrations. As SP, SB, and LY inhibited TNF-a-induced CXCL1 release, we tested whether other MAPK and PI3K inhibitors also had such inhibitory effects. These inhibitors included SU3327 (SU, a JNK inhibitor), LY2228820 (LY, a p38 MAPK inhibitor), and wortmannin (wor, a PI3K inhibitor). However, after examining whether they possessed cytotoxicity, wortmannin was found to cause HUVEC death during a 4-h incubation, and it was therefore excluded from this assay (Figure 3C, right panel). Our results showed that SU and LY inhibited CXCL1 release in a concentration-dependent manner (Figure 3C, left panel). Taken together, we showed the critical roles of JNK, p38 MAPK, PI3K, and the AP1 transcription factor in mediating TNF-a-induced CXCL1 release.

Next, we examined whether the JNK (SP600125), p38 MAPK (SB202190), and PI3K (LY294002) inhibitors had similar effects on TNF-a-induced CXCL1 mRNA expression. Surprisingly, only the JNK inhibitor was able to suppress TNF-a-induced CXCL1 mRNA expression, whereas the p38 MAPK, PI3K, and tyrosine kinase inhibitors did not (Figure 4). The results suggest that TNF-a-induced JNK activation mediates CXCL1 mRNA transcription, whereas the p38 MAPK and PI3K pathways might be related to TNF-a-induced CXCL1 secretion. 

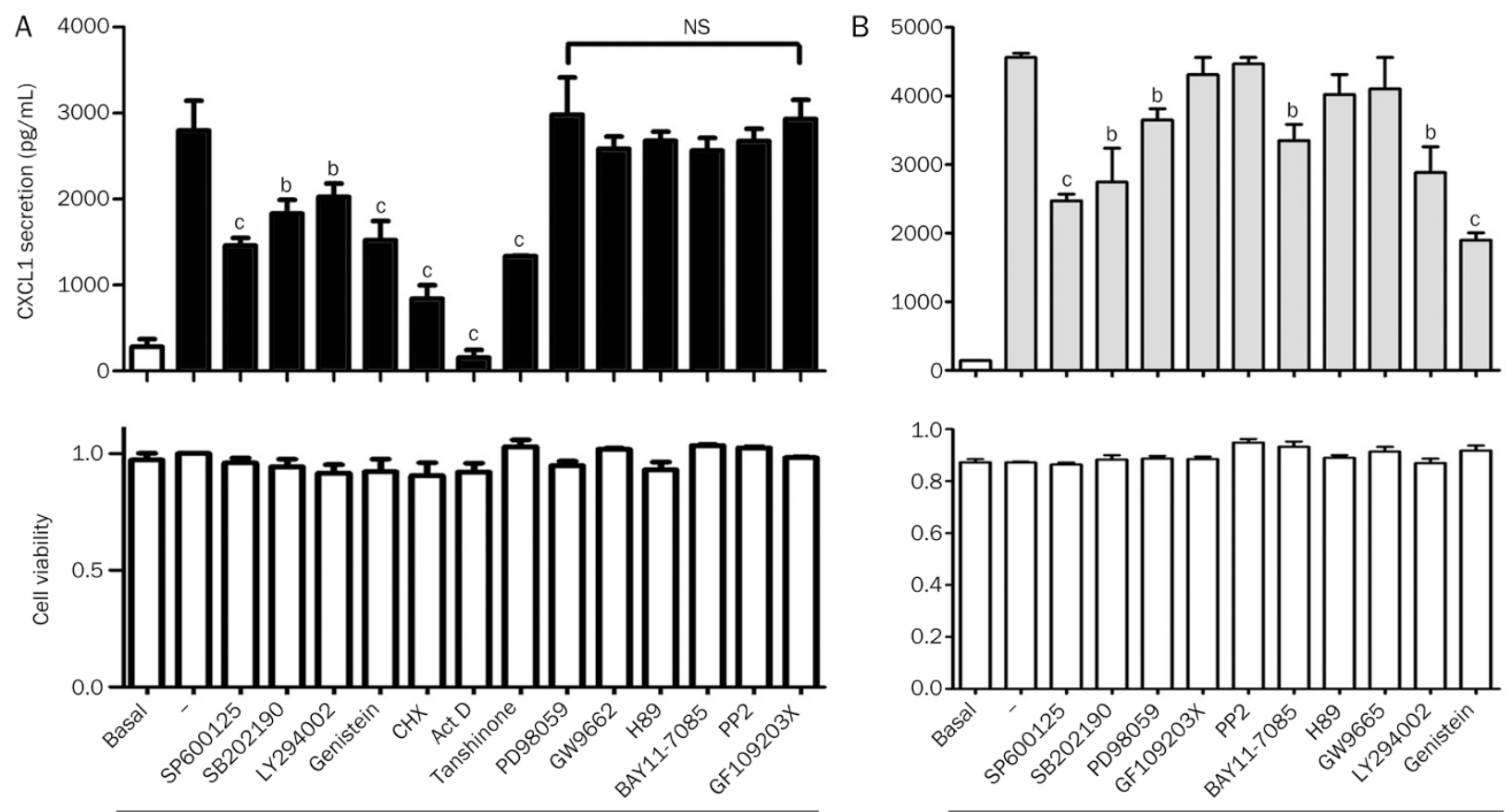

$\operatorname{TNF}-\alpha(5 \mathrm{ng} / \mathrm{mL})$
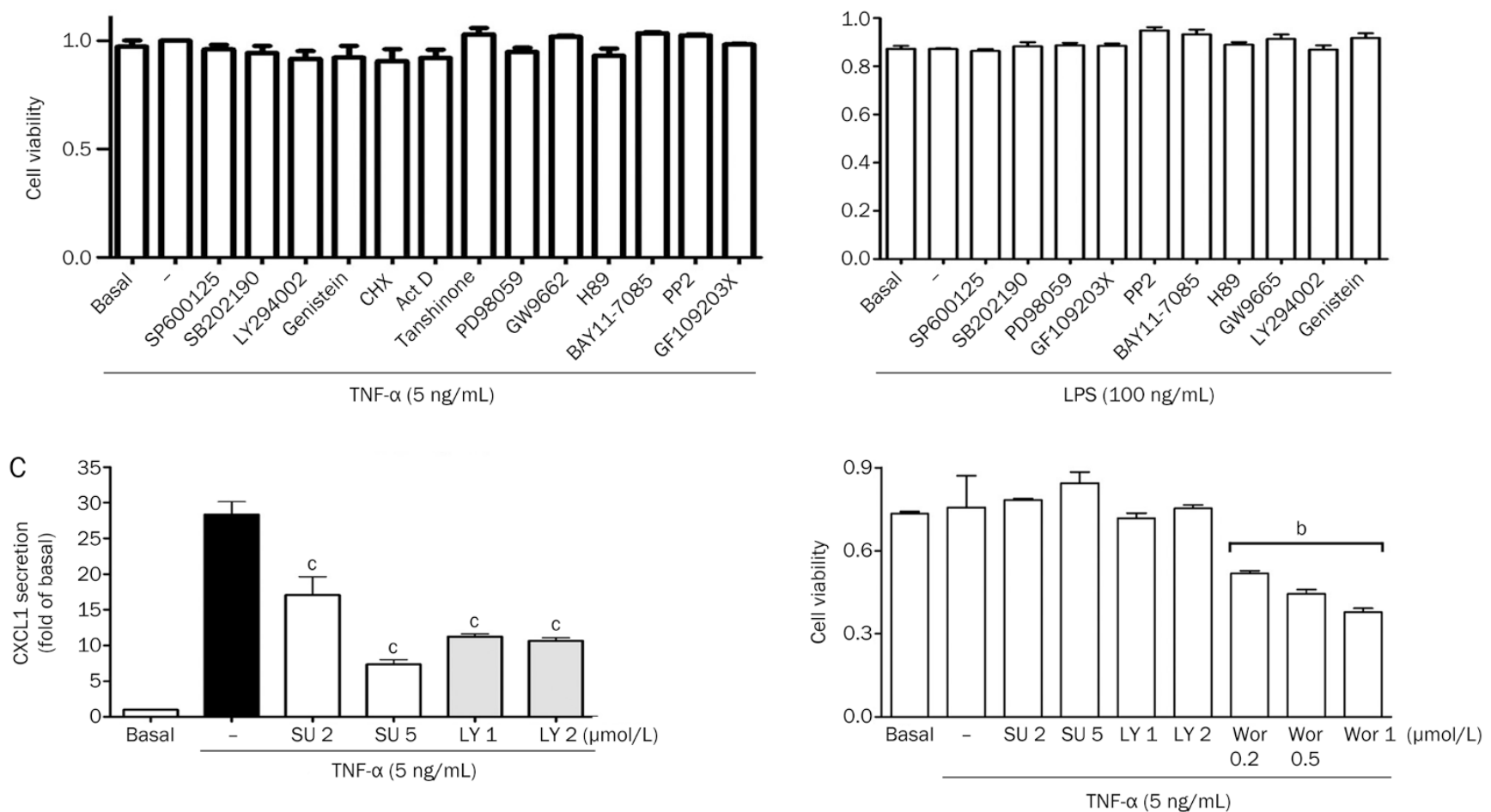

Figure 3. Effects of signaling inhibitors on TNF- $\alpha$-induced CXCL1 secretion. HUVECs were pretreated with various inhibitors for $1 \mathrm{~h}$, followed by (A) PBS (basal) or TNF- $\alpha$ for $6 \mathrm{~h}$ or (B) PBS (basal) or LPS for $4 \mathrm{~h}$. The CXCL1 concentration in the culture media was analyzed by ELISA (upper panel), and the remaining cells were examined by viability assay (lower panel). (C) The effects of the inhibition of JNK, p38 MAPK, and PI-3K on CXCL1 secretion were verified using inhibitors targeting these kinases (left panel). Cell viability was monitored by MTT assay (right panel). Note that wortmannin caused a decrease in cell viability and thus was not included in the CXCL1 secretion assay. The data are the mean \pm SEM $(n=3-5)$. ${ }^{\mathrm{b}} P<0.05,{ }^{\mathrm{c}} P<0.01$ vs TNF- $\alpha$ and vehicle treatment.

TNF- $\alpha$ directly induces JNK, MAPK, PI3K, and Akt activation

As the JNK, p38 MAPK, and PI3K inhibitors reduced TNF- $\alpha$ induced CXCL1 release, we next examined whether TNF- $\alpha$ could directly activate the related signaling pathways in HUVECs. As shown in Figure 5, TNF-a markedly activated JNK, p38 MAPK, PI3K, and Akt in HUVECs. It was found that the TNF-a-induced activation of JNK, p38 MAPK, PI3K, and Akt occurred in a two-phase fashion, which was activated at $5 \mathrm{~min}$ but returned to basal levels at 15-30 min and was followed by an increase at 120-240 $\mathrm{min}$.

Further, we evaluated the activation context of these kinases in response to TNF-a stimulation. As shown in Figure 6A, Western blot analysis demonstrated that SP (a JNK inhibitor) markedly inhibited TNF-a-induced JNK activation and - slightly affected PI3K and Akt activation. By contrast, SB (a p38 MAPK inhibitor) did not affect p38 MAPK activation, but it clearly compromised TNF-a-induced PI3K and Akt activation. Moreover, LY (a PI3K inhibitor) abolished PI3K and Akt activation but did not affect p38 MAPK activation. The inhibitory effects of SB on PI3K and Akt were verified using another p38 inhibitor, LY2228820. As shown in Figure 6B, LY2228820 did not affect p38 MAPK, although it did reduce PI3K and Akt activation. In addition, the short-term incubation of HUVECs with the PI3K inhibitor (wortmannin), which did not cause cell death (data not shown), inhibited TNF signaling in a manner similar to LY294002. To confirm this observation, we showed that JNK and p38 MAPK siRNA slightly affected TNF-a-induced CXCL1 release (Figure 6C). These results, 

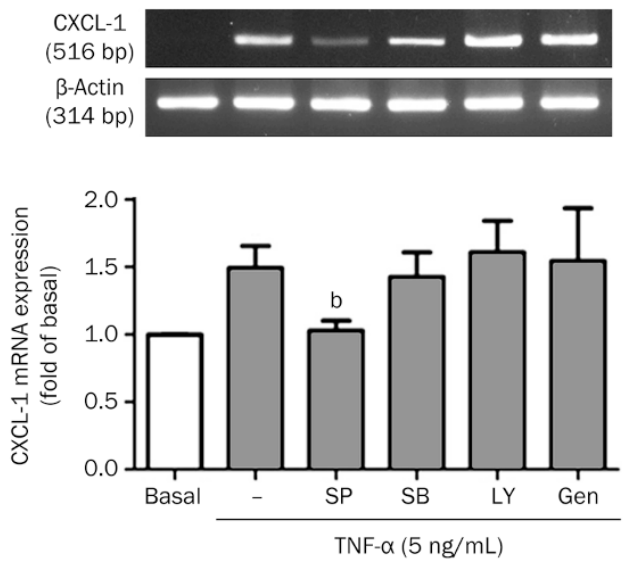

Figure 4. Effect of signaling inhibitors on the CXCL1 mRNA level. HUVECs were pretreated with SP600125 (SP), SB202190 (SB), LY294002 (LY), or genistein (Gen) $(10 \mu \mathrm{mol} / \mathrm{L}$ each) for $1 \mathrm{~h}$, followed by stimulation with TNF- $\alpha(5 \mathrm{ng} / \mathrm{mL})$ for $1.5 \mathrm{~h}$. Total RNA was extracted and analyzed by RTPCR. The data are the mean \pm SEM $(n=3)$. ${ }^{\mathrm{b}} P<0.05$ vs TNF- $\alpha$ and vehicle treatment.

together with the observation that tanshinone IIA (an AP-1 inhibitor) could inhibit TNF-a-induced CXCL1 release (Figure 3), indicated that TNF-a stimulation may have simultaneously activated JNK and p38 MAPK, the activation of one/both of which subsequently leads to AP-1 or PI3K and Akt activation and drives CXCL1 transcription and release.

Effect of dexamethasone on TNF- $\alpha$-induced CXCL1 production It has been reported that dexamethasone inhibits TNF-ainduced CXCL1 secretion in human tracheal smooth muscle cells (HTSMCs) through the induction of MAPK phosphatase-1 (MKP-1) expression and thus dephosphorylates activated JNK, leading to the inactivation of JNK, which is required for CXCL1 transcription ${ }^{[14]}$. Next, we tested whether dexamethasone affected TNF-a-induced CXCL1 release in HUVECs. Strikingly, dexamethasone failed to inhibit TNFa-induced CXCL1 secretion in HUVECs even at a higher concentration of $500 \mathrm{nmol} / \mathrm{L}$ (Figure 7A, left panel). However, it inhibited TNF-a-induced CXCL1 secretion in human lung epithelial cells at a concentration of $10 \mathrm{nmol} / \mathrm{L}$ (right panel). The ineffectiveness of dexamethasone on HUVECs was supported by the observation that it did not affect TNF-a-induced MKP-1 mRNA or protein expression, as determined by RT-PCR and Western blotting, respectively (Figure 7Ba). Moreover, it did not affect TNF-induced JNK and p38 MAPK activation (Figure $7 \mathrm{Bb})$, indicating a differential action of dexamethasone on different cell types.

The effects of CXCL1 on endothelial cell proliferation and monocyte migration

Next, we evaluated the functional role of CXCL1 in endothelial cell proliferation and monocyte migration. As shown in Figure 8A, recombinant CXCL1 was found to significantly induce HUVEC proliferation in a concentration-dependent manner. In addition, a robust increase in the number of migrated monocytes was observed in response to CXCL1 stimulation (Figure $8 \mathrm{~B}$ ). These results suggest that CXCL1 is a chemoattractant for both vascular ECs and monocytes. To further examine whether the released CXCL1 had a similar ability to recruit monocytes, monocyte migration was assayed in a transwell coculture system. As shown in Figure 8C, little monocyte migration was observed under the basal [(-) TNF-a] and control $[(+)$ TNF- $\alpha]$ conditions in the absence of HUVEC coculture. However, migration increased when the cells were cocultured with HUVECs stimulated by TNF-a. As described earlier, CXC receptor 2 (CXCR2) is a counter-receptor for CXCL1. We examined whether a CXCR2 antagonist affected monocyte migration. Migration was inhibited by SB225002 $(\mathrm{SB})$, a selective antagonist of $\mathrm{CXCR} 2^{[15]}$, suggesting that migration requires CXCL1. To further examine the roles of JNK, p38
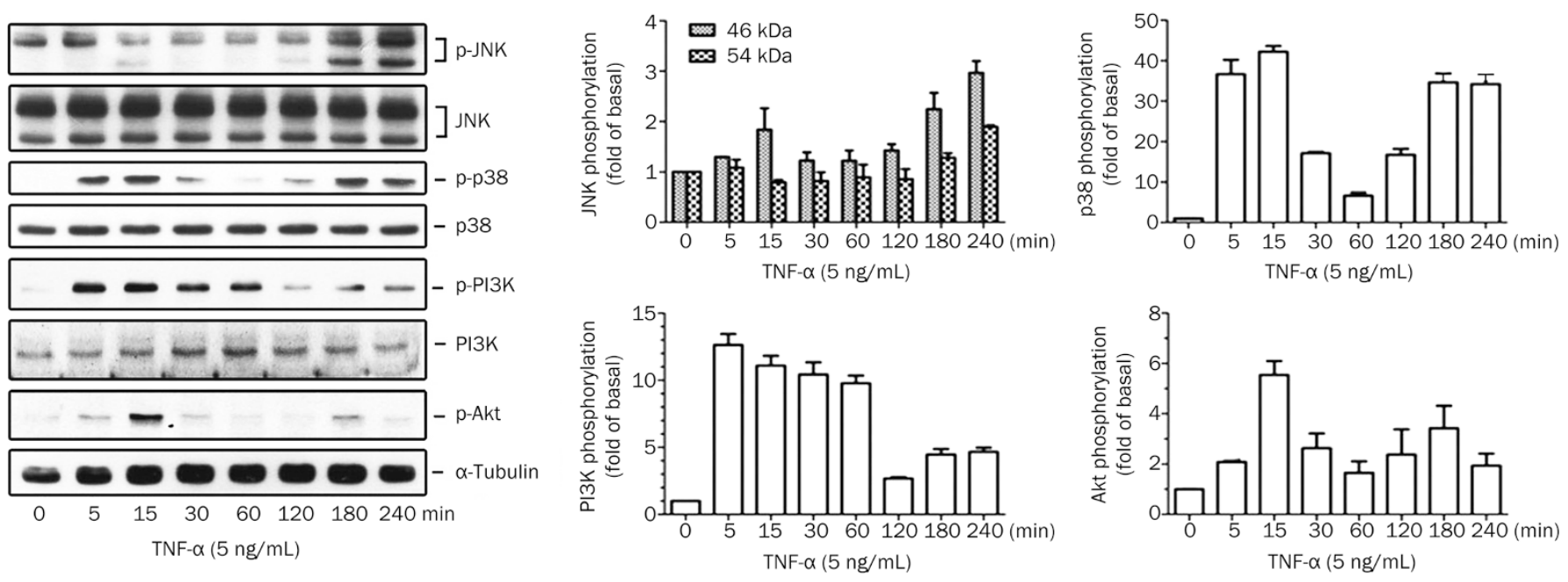

Figure 5. TNF- $\alpha$ induces MAPKs, PI3K, and Akt activation. HUVECs were treated with TNF- $\alpha(5 \mathrm{ng} / \mathrm{mL})$ for the indicated time intervals. After incubation, cell lysates were analyzed by Western blotting. A representative blot is shown, and similar results are quantified by densitometry ( $n=3)$. 

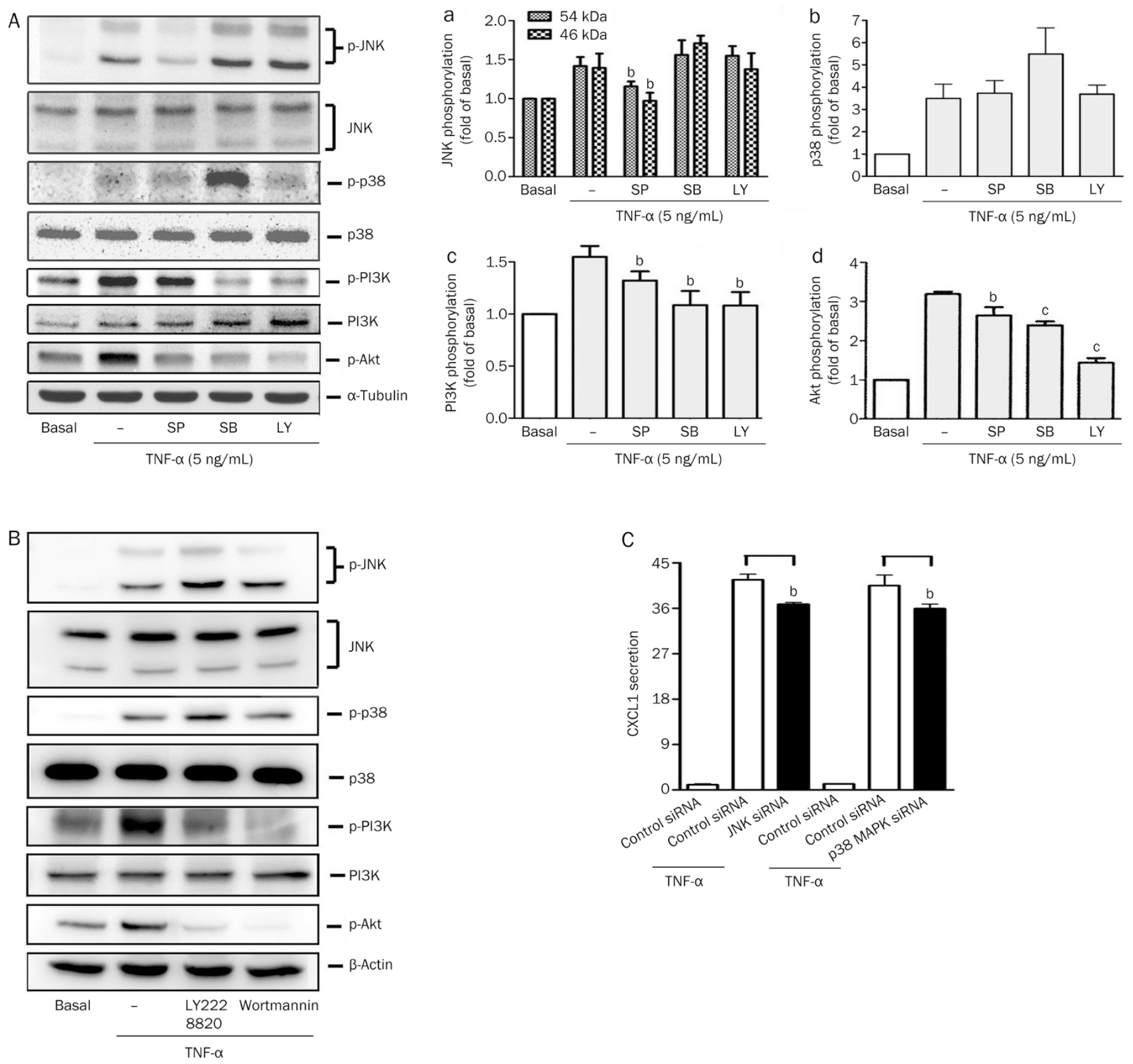

Figure 6. Relationship of JNK, p38 MAPK, and PI3K activation in TNF- $\alpha$-induced signaling. (A) HUVECs were pretreated with SP600125 (SP), SB202190 (SB), or LY294002 (LY) (10 $\mu \mathrm{mol} / \mathrm{L}$ each) for $1 \mathrm{~h}$, followed by stimulation with TNF- $\alpha$ ( $5 \mathrm{ng} / \mathrm{mL})$ for 15 min. A representative blot is shown, and the results are expressed as the mean \pm SEM $(n=3-4)$. (B) Western blot analysis of the effect of another p38 MAPK inhibitor, LY2228820, on TNF- $\alpha$ signaling. HUVECs were pretreated with LY2228820 (10 $\mu \mathrm{mol} / \mathrm{L})$ or wortmannin $(1 \mu \mathrm{mol} / \mathrm{L})$ for $1 \mathrm{~h}$, followed by stimulation with TNF- $\alpha(5 \mathrm{ng} / \mathrm{mL})$ for 15 $\min (n=2)$. (C) The effect of JNK and p38 MAPK siRNA on TNF- $\alpha$-induced CXCL1 secretion $(n=3) .{ }^{b} P<0.05,{ }^{c} P<0.01$ vs TNF- $\alpha$ alone. NS, not significant.

MAPK, and PI-3K in HUVEC-induced monocyte migration, the assay was performed in the presence of their respective signaling inhibitors. As shown in Figure 8D, these inhibitors markedly suppressed HUVEC-induced monocyte migration.

\section{Discussion}

In this study, we screened various proinflammatory mediators (IP-10, SDF-1, TNF- $\mathrm{a}$ ), growth factors (VEGF, bFGF, EGF, and IGF), and vasoactive agents (leptin, thrombin, Ang II, TXA analog, ATP, and ADP). As previously reported by others ${ }^{[9]}$, we found that TNF-a, LPS, and thrombin could induce CXCL1 release by HUVECs (Figure 1). Our results also revealed that some growth factors and vasoactive agents known to affect the cardiovascular system were unable to promote CXCL1 expression. The most important finding in this study was the elucidation of the mechanism of CXCL1 induction by TNF-a, which occurred through the activation of JNK, p38 MAPK, and PI3K. Recombinant and released CXCL1 were able to 
A

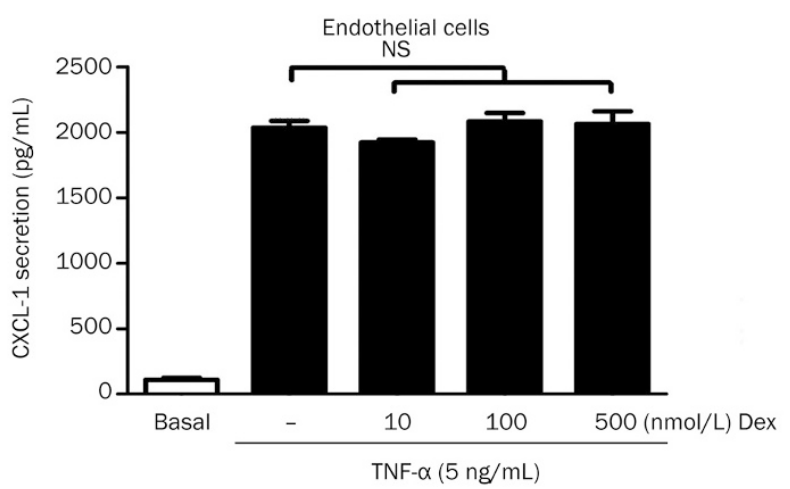

B a

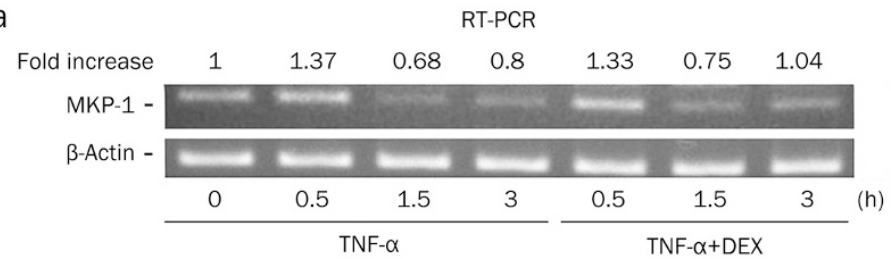

b
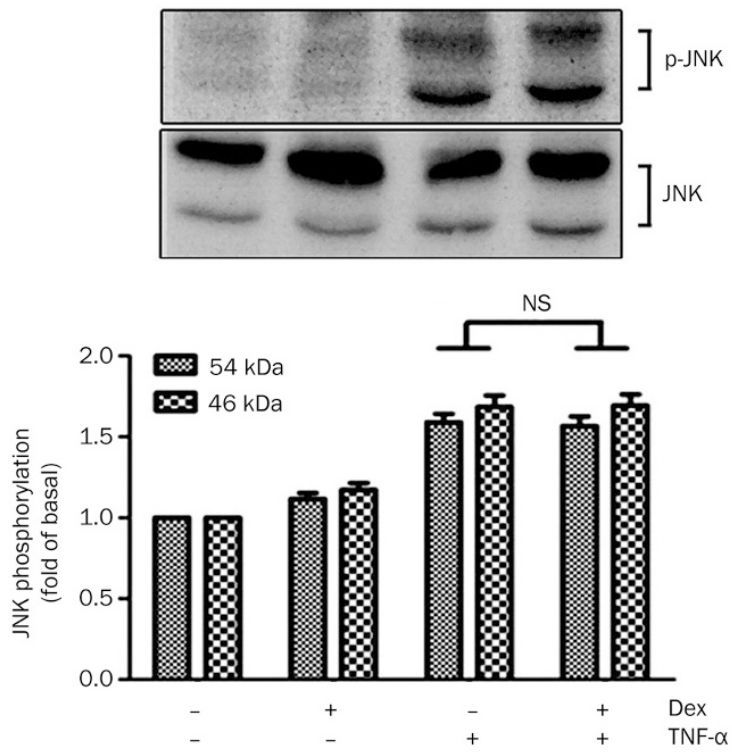
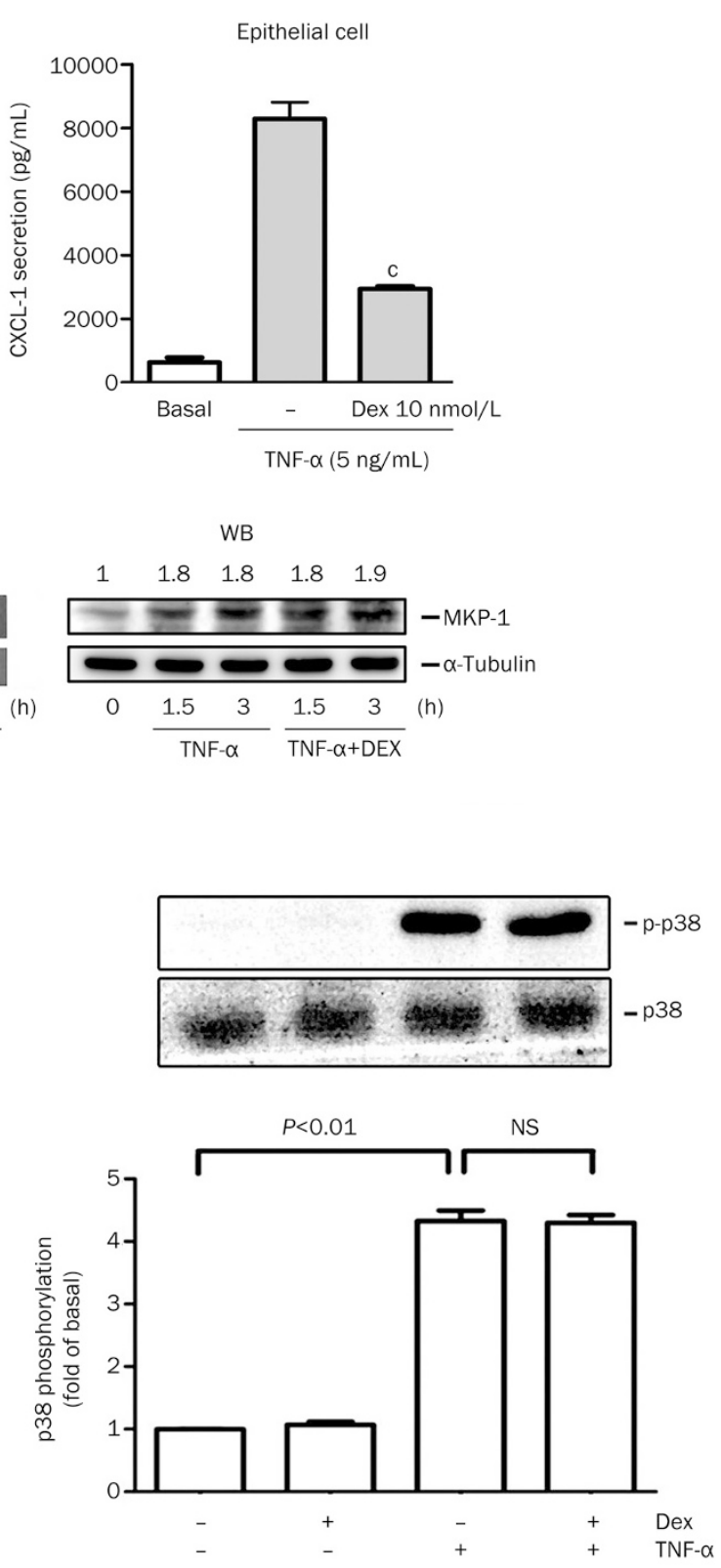

Figure 7. Effects of dexamethasone on TNF- $\alpha$-induced CXCL1 secretion and signaling. (A) HUVECs (left) and human A549 epithelial cells (right) were treated with TNF- $\alpha$ in the absence or presence of dexamethasone (Dex) for $6 \mathrm{~h}$. The CXCL1 concentration in the culture media was analyzed by ELISA. (B) HUVECs were pretreated with Dex $(500 \mathrm{nmol} / \mathrm{L})$ for $30 \mathrm{~min}$, followed by stimulation with TNF- $\alpha(5 \mathrm{ng} / \mathrm{mL})$ for (a) the indicated time intervals or (b) 15 min. The cells were collected and analyzed by RT-PCR or Western blotting (WB). The PCR products of MKP-1 and $\beta$-actin were 219 and 314 bp, respectively (n=3-4). ${ }^{\mathrm{b}} P<0.05,{ }^{\mathrm{c}} P<0.01$ vs TNF- $\alpha$ alone. NS, not significant.

promote HUVEC proliferation and to attract monocyte migration (Figure 8), suggesting a functional role of CXCL1 secreted by endothelial cells in response to TNF- $\alpha$.

Based on our results, we suggested that the inductive effects of TNF-a were mediated through the regulation of cellular transcription and secretion by JNK, p38 MAPK, and PI3K activation. It has been shown that NF-kB mediates the IL-1/TNFa-induced production of CXCL1 by human fibroblasts ${ }^{[16]}$ and that protein kinase D1 (PKD1, also named PKC- $\mu$ ) mediates the TNF-a-induced production of proinflammatory cytokines such as CXCL1, CXCL8, and IL-6 in human vascular endothelial cells ${ }^{[17]}$. Moreover, staurosporine, a protein kinase C (PKC) inhibitor, attenuates the production of CXCL1 by thrombin and phorbol 12-myristate 13-acetate (PMA) but does not affect the action of IL-1 beta ${ }^{[18]}$. Wen et al have also suggested that PKC is involved in CXCL1 expression in HUVECs because 12-O-tetradecanoylphorbol-13-acetate (TPA), which activates PKC, has a mild inductive effect on CXCL1 expression ${ }^{[9]}$. In this study, however, the general PKC inhibitor GF109203X and the PKA inhibitor H-89 did not affect TNF-a-induced CXCL1 
A

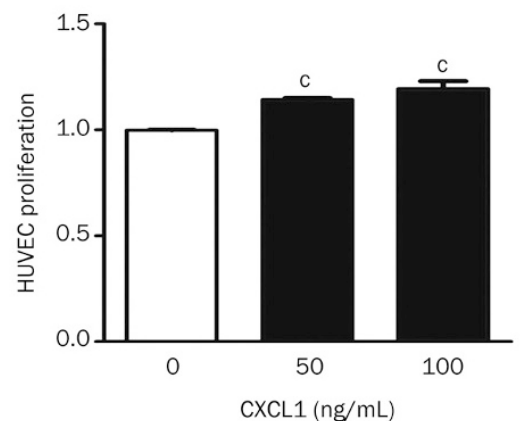

C
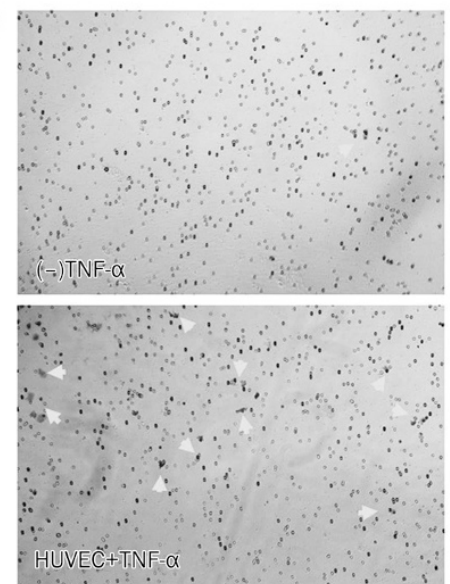

D
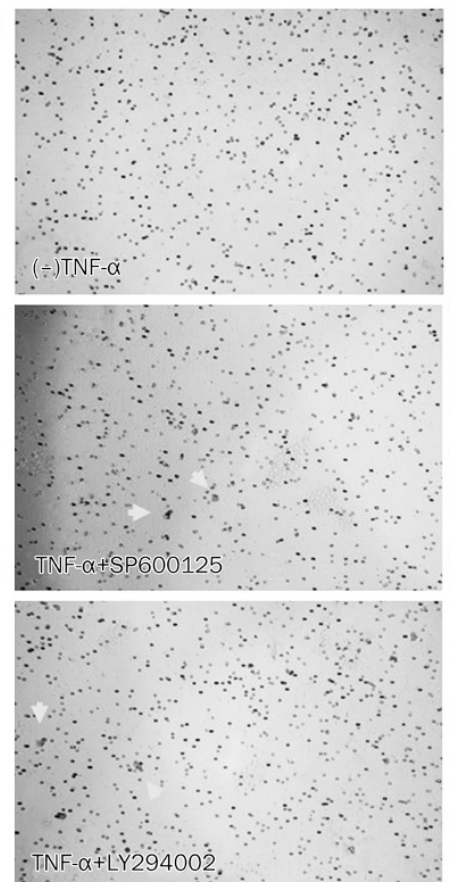
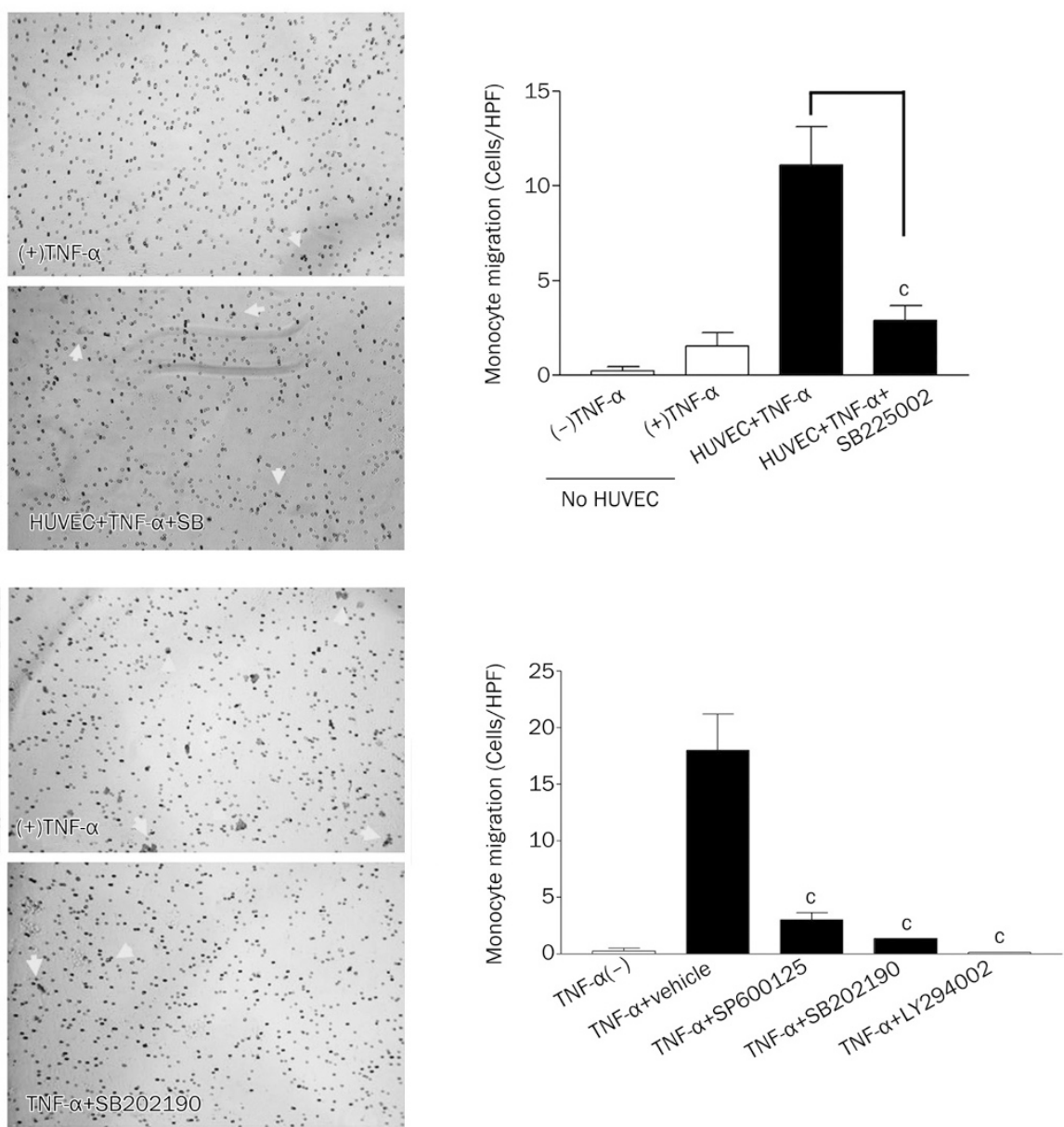

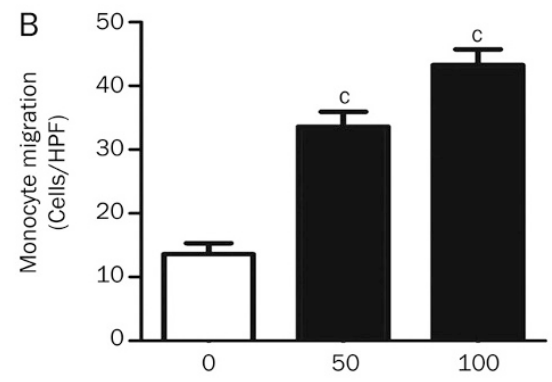

CXCL1 (ng/mL)

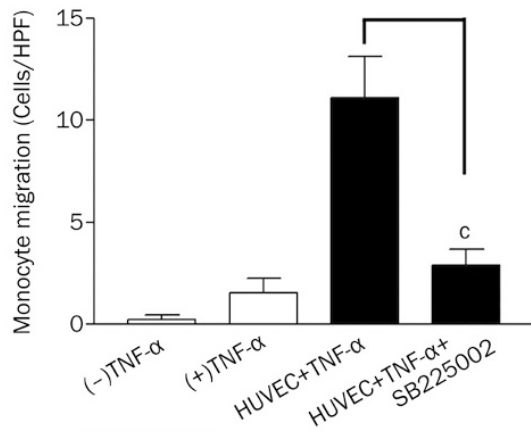

No HUVEC 
release (Figure 3), suggesting that the process did not involve PKA, PKC, or PKD. In addition, BAY11-7085, which targets NF-KB, did not inhibit TNF-a-induced CXCL1 secretion, suggesting that NF-kB participation in this process is unlikely. Interestingly, BAY11-7085 inhibited LPS-induced CXCL1 secretion, indicating that the concentration used in this study is effective and that NF-KB plays a role in LPS-induced but not TNF- $\alpha$-induced CXCL1 production by HUVECs. TNF- $\alpha$ induces CXCL1 expression through transcriptional regulation, which was primarily demonstrated by the following observations. First, TNF- $a$ enhanced CXCL1 mRNA transcription during the early stage of treatment (Figure 2C). Second, a gene transcription inhibitor (Act D) and a protein translation inhibitor (CHX) attenuated TNF-a-induced CXCL1 protein expression (Figure 3).

TNF-a-induced CXCL1 production was inhibited by JNK inhibitors (SP600125 and SU3327), p38 MAPK inhibitors (SB202190 and LY2228820), a PI3K inhibitor (LY294002), a tyrosine kinase inhibitor (genistein), and an AP-1 transcription factor inhibitor (tanshinone IIA) but not by other inhibitors (Figure 3). Moreover, TNF-a directly activated JNK, p38 MAPK, PI3K, and Akt in HUVECs (Figure 5). However, only the JNK inhibitor reduced TNF-a-induced CXCL1 mRNA expression (Figure 4). c-Jun is a component of the transcription factor AP-1, and AP-1 is composed of dimers of Fos, Jun, and ATF family members ${ }^{[19]}$. JNK, when active as a dimer, can translocate to the nucleus and regulate transcription through its effects on AP- 1 transcription factors ${ }^{[20,21]}$. It has been reported that CXC-ELR chemokines have both NF-KB- and $\mathrm{AP}-1$-binding sites in their promoter regions ${ }^{[22-24]}$. Our results demonstrated that tanshinone IIA, targeting AP-1, markedly inhibited TNF-a-induced CXCL1 release. Therefore, the findings suggest that TNF-a regulates CXCL1 release through two differential pathways, one affecting gene expression through JNK and its downstream AP-1 transcription factor and the other influencing cellular CXCL1 secretion into the extracellular space, primarily through p38 MAPK and PI3K activation. This hypothesis could be supported by the results presented in Figures 5 and 6, which show that JNK and p38 MAPK were independently regulated by TNF- $\alpha$ and were activated before PI3K and Akt, as determined by Western blotting. It is also supported by the observation that siRNAs targeting JNK and p38 MAPK reduced TNF-a-induced CXCL1 secretion (Figure 5C). The lower extent of inhibition possibly resulted from a lower transfection efficiency and the presence of several kinase isoforms. Based on these findings, TNF- $\alpha$ appears to act in a manner different from VEGF to induce CXCL1 production by HUVECs $^{[17]}$, although with a regulatory mechanism similar to VEGF in A549 cells $^{[25]}$. The lower extent of inhibition may also be related to the specificity of these inhibitors, particularly the p38 MAPK inhibitor (SB), because it did not block TNF-a-induced p38 MAPK activation, but it did reduce PI-3K and Akt activation (Figure 5A). This particular p38 inhibitor, SB202190, has been shown to inhibit anisomycin-induced p38 MAPK phosphorylation ${ }^{[26]}$. However, SB202190 and its structurally related pyridinylimidazole compound SB203580 does not inhibit TNF-induced p38 MAPK phosphorylation in several cell types and instead increases the phosphorylation of p38 MAPK ${ }^{[27]}$. A similar observation has been reported for another p38 inhibitor (LY2228820) used in this study, which is a highly selective ATP-competitive inhibitor of $p 38 a / \beta$ that does not alter p38 MAPK activation but reduces downstream p38 MAPK signaling ${ }^{[28]}$. In addition, the short-term incubation of HUVECs with a PI3K inhibitor (wortmannin) inhibited TNF signaling, similar to LY294002 (Figure 6B). Therefore, our results confirm the specificity of these inhibitors, suggesting that JNK, p38, and PI3K are the key players in TNF-a-induced CXCL1 secretion in HUVECs. However, the precise regulatory mechanism of p38 MAPK and the downstream PI3K in regulating CXCL1 secretion remains to be further investigated. To date, little is known about the secretory pathways responsible for chemokine release, although some studies have shown that the storage and release of CXCL8 from secretory vesicles are dependent on endocytosis during the late stages of neutrophil development in the bone marrow ${ }^{[29,30]}$.

Another interesting finding from the present study is that dexamethasone failed to inhibit TNF-a-induced CXCL1 release in HUVECs but not in human epithelial cells (Figure 7). A previous study has shown that dexamethasone inhibits TNF-a-induced CXCL1 secretion in HTSMCs through the induction of MKP-1 expression and thus dephosphorylates phosphorylated JNK, leading to the inactivation of JNK, which is required for CXCL1 transcription ${ }^{[14]}$. We found that dexamethasone did not alter MKP-1 mRNA and protein expression in HUVECs or affect TNF-a-induced JNK and p38 activation. This was not due to the ineffectiveness of the dexamethasone because it inhibited TNF-a-induced CXCL1 release and enhanced MKP-1 expression in human A549 epithelial cells (Figure 7 and our unpublished data). Why dexamethasone has differential effects among cell types is an interesting issue that requires further investigation.

In conclusion, in the present study, we demonstrated that TNF- $\alpha$ induced CXCL1 mRNA and protein expression in HUVECs through JNK-, p38 MAPK-, and PI3K-dependent pathways. We suggest that JNK activation is essential for CXCL1 synthesis, whereas p38 MAPK and PI3K activation may be required for controlling CXCL1 release into the extracellular space. A proposed scheme of the effects of TNF- $\mathrm{a}$ on CXCL1 release is provided in Figure 9. The induction of CXCL1 release by TNF-a in HUVECs may functionally lead to HUVEC proliferation and the recruitment of monocytes into the local microenvironment. Our results reveal the contribution of TNF- $a$ and elucidate its possible mechanism in the induction of CXCL1 release.

\section{Acknowledgements}

The work was supported by a research grant (SKH-830299-DR-05) from Shin Kong Wu Ho-Su Memorial Hospital, Taipei, Taiwan, China.

\section{Author contribution}

Huey-ming LO designed and performed some of the experi- 


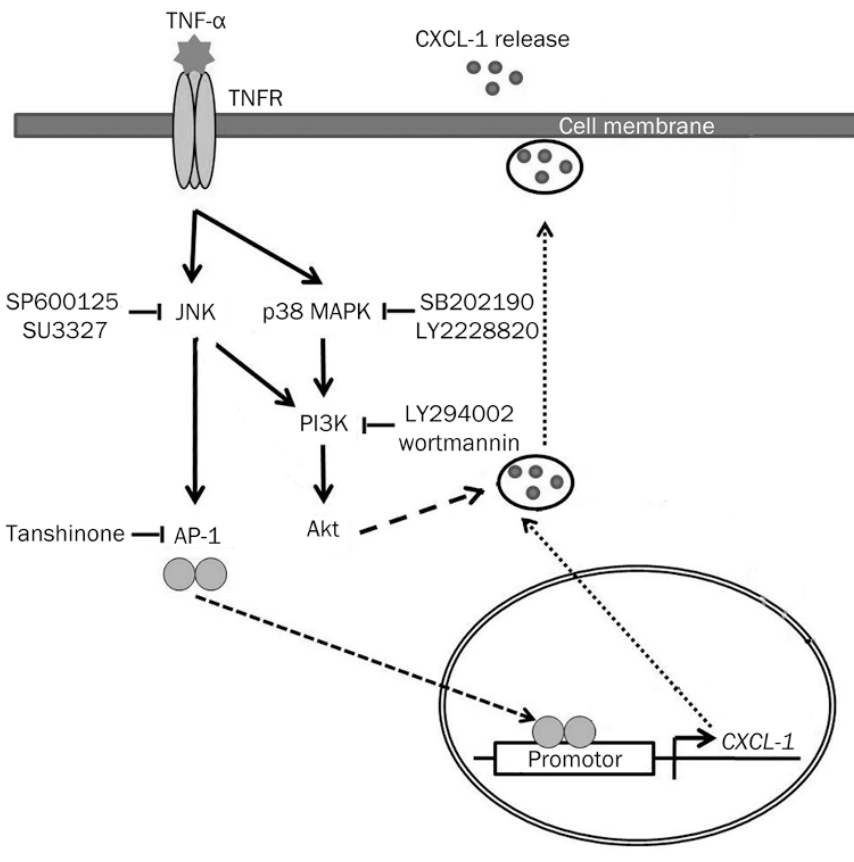

Figure 9. Scheme of TNF- $\alpha$ signaling enhancing CXCL1 release in human endothelial cells. TNF- $\alpha$ induced JNK and p38 MAPK activation. JNK was responsible for the activation of the AP-1 transcription factor and for driving the CXCL1 transcription machinery, whereas p38 MAPK was responsible for $\mathrm{PI} 3 \mathrm{~K}$ and Akt activation, which was essential for CXCL1 release. The intracellular signaling molecules affected by the inhibitors are indicated. Solid arrows: this study. Dashed arrows: suggestive.

ments; Tsung-hsuan LAI collected the human umbilical cords, prepared the HUVEC cultures, and performed the data analysis; Chih-hung LI performed the ELISA, Western blotting, and RT-PCR experiments; and Wen-bin WU designed the experiments, provided supervision, performed the data analysis, and wrote the paper.

\section{Abbreviations}

ERK, extracellular matrix-regulated kinase; HUVECs, human umbilical vein endothelial cells; JNK, c-Jun N-terminal kinase; MAPK, mitogen-activated protein kinase; PI3K, phosphoinositide-3 kinase; TNF: tumor necrosis factor.

\section{References}

1 Wang $X$, Lin $Y$. Tumor necrosis factor and cancer, buddies or foes[quest]. Acta Pharmacol Sin 2008; 29: 1275-88.

2 DePalma RG, Hayes VW, Cafferata HT, Mohammadpour HA, Chow $\mathrm{BK}$, Zacharski LR, et al. Cytokine signatures in atherosclerotic claudicants. J Surg Res 2003; 111: 215-21.

3 McKellar GE, McCarey DW, Sattar N, Mclnnes IB. Role for TNF in atherosclerosis? Lessons from autoimmune disease. Nat Rev Cardiol 2009; 6: 410-7.

4 Balkwill F, Mantovani A. Inflammation and cancer: back to Virchow? Lancet 2001; 357: 539-45.

5 Charo IF, Ransohoff RM. The many roles of chemokines and chemokine receptors in inflammation. New Engl J Med 2006; 354: 610-21.

6 Baggiolini M. Chemokines in pathology and medicine. J Int Med
2001; 250: 91-104.

7 Nannuru KC, Singh S, Singh RK. Chemokines and metastasis the tumor microenvironment. In: Bagley RG, editor. New York: Springer; 2010. p 601-31.

8 Scapini P, Morini M, Tecchio C, Minghelli S, Di Carlo E, Tanghetti E, et al. CXCL1/macrophage inflammatory protein-2-induced angiogenesis in vivo is mediated by neutrophil-derived vascular endothelial growth factor-A. J Immunol 2004; 172: 5034-40.

9 Wen DZ, Rowland A, Derynck R. Expression and secretion of gro/ MGSA by stimulated human endothelial cells. EMBO J 1989; 8: 1761-6.

10 Breland UM, Halvorsen B, Hol J, Øie E, Paulsson-Berne G, Yndestad A, et al. A potential role of the CXC chemokine Groo in atherosclerosis and plaque destabilization. Arteriosclerosis Thromb Vasc Biol 2008; 28: 1005-11.

11 Caunt M, Hu L, Tang T, Brooks PC, Ibrahim S, Karpatkin S. Growthregulated oncogene is pivotal in thrombin-induced angiogenesis. Cancer Res 2006; 66: 4125-32.

12 Wu WB, Hung DK, Chang FW, Ong ET, Chen BH. Anti-inflammatory and anti-angiogenic effects of flavonoids isolated from Lycium barbarum Linnaeus on human umbilical vein endothelial cells. Food Function 2012; 3: 1068-81.

13 Chen CP, Hung CF, Lee SC, Lo HM, Wu PH, Wu WB. Lycopene binding compromised PDGF-AA/-AB signaling and migration in smooth muscle cells and fibroblasts: prediction of the possible lycopene binding site within PDGF. Naunyn-Schmiedeberg's Arch Pharmacol 2010; 381: 401-14.

14 Issa R, Xie S, Khorasani N, Sukkar M, Adcock IM, Lee KY, et al. Corticosteroid inhibition of growth-related oncogene protein- $\alpha$ via mitogenactivated kinase phosphatase- 1 in airway smooth muscle cells. J Immunol 2007; 178: 7366-75.

15 Alexander SP, Mathie A, Peters JA. Guide to receptors and channels (GRAC), 5th edition. Br J Pharmacol 2011; 164 Suppl 1: S1-324.

16 Anisowicz A, Messineo M, Lee SW, Sager R. An NF-kappa B-like transcription factor mediates IL-1/TNF-alpha induction of Gro in human fibroblasts. J Immunol 1991; 147: 520-7.

17 Hao Q, Wang L, Tang $\mathrm{H}$. Vascular endothelial growth factor induces protein kinase D-dependent production of proinflammatory cytokines in endothelial cells. Am J Physiol 2009; 296: C821-C27.

18 Murakami K, Ueno A, Yamanouchi K, Kondo T. Thrombin induces GRO $\alpha$ MGSA production in human umbilical vein endothelial cells. Thrombosis Res 1995; 79: 387-94.

19 Jochum W, Passegue E, Wagner EF. AP-1 in mouse development and tumorigenesis. Oncogene 2001; 20: 2401-12.

20 Leppa S, Bohmann D. Diverse functions of JNK signaling and c-Jun in stress response and apoptosis. Oncogene 1999; 18: 6158-62.

21 Kyriakis JM, Avruch J. Mammalian mitogen-activated protein kinase signal transduction pathways activated by stress and inflammation. Physiol Rev 2001; 81: 807-69.

22 Walpen S, Beck KF, Schaefer L, Raslik I, Eberhardt W, Schaefer RM, et al. Nitric oxide induces MIP-2 transcription in rat renal mesangial cells and in a rat model of glomerulonephritis. FASEB J 2001; 15: 571-3.

23 Roebuck KA, Carpenter LR, Lakshminarayanan V, Page SM, Moy JN, Thomas LL. Stimulus-specific regulation of chemokine expression involves differential activation of the redox-responsive transcription factors AP-1 and NF-kappaB. J Leukocyte Biol 1999; 65: 291-8.

24 Shi MM, Chong I, Godleski JJ, Paulauskis JD. Regulation of macrophage inflammatory protein-2 gene expression by oxidative stress in rat alveolar macrophages. Immunology 1999; 97: 309-15.

25 Lo HM, Shieh JM, Chen CL, Tsou CJ, Wu WB. Vascular endothelial 
growth factor induces CXCL1 chemokine release via JNK and PI-3Kdependent pathways in human lung carcinoma epithelial cells. Int J Mol Sci 2013; 14: 10090-106.

26 Geiger PC, Wright DC, Han DH, Holloszy JO. Activation of p38 MAP kinase enhances sensitivity of muscle glucose transport to insulin. Am Physiol Endocrinol Metab 2005; 288: E782-8.

27 Kumar S, Jiang MS, Adams JL, Lee JC. Pyridinylimidazole compound SB 203580 inhibits the activity but not the activation of p38 mitogenactivated protein kinase. Biochem Biophys Res Commun 1999; 263 : 825-31.

28 Ishitsuka K, Hideshima T, Neri P, Vallet S, Shiraishi N, Okawa Y, et al. p38 mitogen-activated protein kinase inhibitor LY2228820 enhances bortezomib-induced cytotoxicity and inhibits osteoclastogenesis in multiple myeloma; therapeutic implications. Br J Haematol 2008; 141: 598-606.

29 Kuhns DB, Gallin Jl. Increased cell-associated IL-8 in human exudative and A23187-treated peripheral blood neutrophils. J Immunol 1995; 154: 6556-62.

30 Pellmé S, Mörgelin M, Tapper H, Mellqvist UH, Dahlgren C, Karlsson A. Localization of human neutrophil interleukin-8 (CXCL-8) to organelle(s) distinct from the classical granules and secretory vesicles. J Leukocyte Biol 2006; 79: 5647-3. 